\title{
Effects of preoperative oral carbohydrate administration on patient well-being and satisfaction in thyroid surgery
}

\author{
A Ram Doo, Hyunsup Hwang, Min-Jong Ki, Jun-Rae Lee, and Dong-Chan Kim \\ Department of Anesthesiology and Pain Medicine, Chonbuk National University Medical School and Hospital, \\ Jeonju, Korea
}

\begin{abstract}
Background: Although the positive effects of preoperative oral carbohydrate administration on clinical outcomes following major surgery have been reported continuously, there are few investigations of them in minor surgical patients. The present study was designed to examine the effects of preoperative oral carbohydrate administration on patient well-being and satisfaction in patients undergoing thyroidectomy.

Methods: Fifty adults aged 20-65 years and scheduled for elective thyroidectomy in first schedule in the morning were allocated to one of two groups. The Control group $(n=25)$ was requested to obey traditional preoperative fasting after midnight prior to the day of surgery. The Carbohydrate group $(\mathrm{n}=25)$ also fasted overnight but drank $400 \mathrm{ml}$ of carbohydrate-rich drink 2 hours before induction of anesthesia. Patient well-being (thirst, hunger, mouth dryness, nausea and vomiting, fatigue, anxiety and sleep quality) and satisfaction were assessed just before the operating room admission (preoperative) and 6 hours following surgery (postoperative). Other secondary outcomes including oral Schirmer's test and plasma glucose concentrations were also evaluated.

Results: The two groups were homogenous in patient characteristics. Seven parameters representing patient well-being evaluated on NRS (0-10) and patient satisfaction scored on a 5-point scale were not statistically different between the two groups preoperatively and postoperatively. There were no statistically significant differences in secondary outcomes. Conclusions: Preoperative oral carbohydrate administration does not appear to improve patient well-being and satisfaction compared with midnight fasting in patients undergoing thyroidectomy in first schedule in the morning.
\end{abstract}

Keywords: Carbohydrate; Fasting; Glucose; Patient satisfaction; Thyroidectomy.

Corresponding author: Dong-Chan Kim, M.D., Ph.D.

Department of Anesthesiology and Pain Medicine, Chonbuk National University Medical School and Hospital, 20 Gunji-ro, Deokjin-gu, Jeonju 54907, Korea

Tel: 82-63-250-1241, Fax: 82-63-250-1240

Email: dckim@chonbuk.ac.kr

ORCID: https://orcid.org/0000-0002-6881-126X

Received: June 13, 2017.

Revised: July 21, 2017 (1st); August 7, 2017 (2nd).

Accepted: August 22, 2017.

Korean J Anesthesiol 2018 October 71(5): 394-400

https://doi.org/10.4097/kja.d.18.27143

\section{Introduction}

Midnight fasting before surgery has been a standard practice for patients receiving elective surgery with the expectation for minimizing the possibility of unintended aspiration of gastric contents by emptying the stomach. However, it is not supported by any scientific evidence. In fact, data from meta-analysis including systemic reviews concluded that midnight fasting dose not reduce the volume and acidity of stomach content during surgery [1-3]. Recent advances in perioperative medicine have led to the recommendation of liberal fasting and preoperative oral carbohydrate ingestion as a part of Enhanced Recovery

(c) This is an open-access article distributed under the terms of the Creative Commons Attribution Non-Commercial License (http://creativecommons.org/ licenses/by-nc/4.0/), which permits unrestricted non-commercial use, distribution, and reproduction in any medium, provided the original work is properly cited. 
After Surgery (ERAS) protocols. The ERAS program was developed to facilitate postoperative recovery by reducing stress response for colon surgery patients, which includes various components of perioperative recommendations [4]. Especially, ERAS recommends that preoperative oral carbohydrate loading should be routinely provided to patients undergoing elective colon surgery.

Preoperative oral carbohydrate administration is known to reduce metabolic stress and insulin resistance postoperatively [5-7], reduce hospital stay [8,9], improve patient well-being $[10,11]$, and maintain lean body mass and muscle strength [12] in patients undergoing major abdominal, orthopedic and cardiac surgery. However, there are few investigations whether preoperative oral carbohydrate administration positively impacts patient outcome in minor surgical patients.

In the present study, we hypothesized that preoperative oral carbohydrate administration will improve well-being and satisfaction of patients undergoing elective thyroid surgery.

\section{Materials and Methods}

This study was approved by the relevant Institutional Review Board. After obtaining informed consent, 50 patients aged 20-65 years with American Society of Anesthesiologists physical status I or II, who were scheduled to undergo open thyroidectomy under general anesthesia were enrolled in this singleblinded, randomized, prospective study. Only patients who scheduled for the first operation in the morning were assessed for enrollment. Patients with a history of type I or II diabetes mellitus, gastric emptying disorders including gastroesophageal reflux disease, contraindications for ketorolac or nefopam, or emergency surgery were excluded. Patients with fasting blood glucose $\geq 126 \mathrm{mg} / \mathrm{dl}$ or glycosylated hemoglobin $\geq 6.5 \%$ on preoperative laboratory test, suggestive of hidden diabetes mellitus, were also excluded.

After obtaining informed consent, the participants were randomly allocated to one of two groups: control group or carbohydrate group. Subjects in the control group were requested to obey traditional preoperative fasting after midnight prior to the day of surgery. Subjects in the carbohydrate group also fasted, but received $400 \mathrm{ml}$ of carbohydrate-rich drink (12.8\% carbohydrates, $50 \mathrm{kcal} / 100 \mathrm{ml}$; Nucare NONPO ${ }^{\circledR}$, Daesang Wellife, Korea) 2 hours before induction of anesthesia.

The anesthetic regimen was standardized for all participants. Anesthesia was induced with propofol $1.5-2 \mathrm{mg} / \mathrm{kg}$ and rocuronium $0.6 \mathrm{mg} / \mathrm{kg}$, and maintained with sevoflurane and 50\% oxygen in air. Sevoflurane was administrated at end-tidal concentrations of $0.5-4.0 \%$ during the operation to maintain non-invasive arterial pressure and heart rate within preanesthetic values. End-tidal carbon dioxide partial pressure was maintained at
30-35 mmHg. On the morning of the surgery, intravenous fluid administration was started via peripheral venous catheter, and the fluid was limited to glucose-free solution for all participants. It was maintained at a rate of $4 \mathrm{ml} / \mathrm{h} / \mathrm{kg}$ during the operation. At the end of surgery, anesthetics were stopped and residual neuromuscular block was antagonized with neostigmine $50 \mu \mathrm{g} / \mathrm{kg}$ and glycopyrrolate $10 \mu \mathrm{g} / \mathrm{kg}$ at T2 appearance in the train-of-four count. Postoperative analgesia was achieved with patient-controlled analgesia (PCA) containing ketorolac (Trolac, Whanin Pham Co., Korea) and nefopam (Acupan, Pharmbio Korea, Korea).

\section{Primary endpoints}

\section{Assessment of patient well-being and satisfaction}

Seven parameters representing patient well-being (thirst, hunger, mouth dryness, nausea and vomiting, fatigue, anxiety, and sleep quality) were assessed using numeric rating scale (NRS; 0 : no discomfort, 10: worst imaginable discomfort) by a simple questionnaire. The patients were assessed twice. To investigate preoperative well-being, the questionnaire was completed just before the operating room admission in the ward. Postoperative well-being was assessed at 6 hours following surgery in the same way. Patient satisfaction also was measured using a 5-point scale (5: very satisfied, 4: somewhat satisfied, 3: neutral, 2: somewhat dissatisfied, 1: very dissatisfied) at the time. All patient-reported outcomes were assessed by the same investigator blinded to the allocated groups.

\section{Secondary endpoints}

\section{Oral Schirmer's test}

Upon arrival at the operating room for surgery, oral Schirmer's test was performed in all patients of both groups as described previously [13]. In brief, whatman 41 Filter paper was placed on the patients' mouth floor just after swallowing with the patient in a sitting position. Saliva secreted from the salivary glands was absorbed by the filter paper for 5 minutes. Secretory capacity in $\mathrm{mm}$ during the 5 -minute period was determined.

\section{Blood glucose}

Blood glucose level obtained by finger stick testing (Ac$\mathrm{cu} \mathrm{Chek}^{\circledR}$, Roche Diagnostics, Germany) was recorded at six time points: 2 hours before anesthesia induction (baseline), just before administration of the carbohydrate-rich drink for the carbohydrate group, 1 hour before anesthesia induction (T1), at anesthesia induction (T2), 1 hour after anesthesia induction (T3), 2 hours after anesthesia induction (T4), and 3 hours after anesthesia induction (T5). Intra-individual glucose variability was evaluated using the coefficient of glucose variation. Coeffi- 
cient of glucose variation (\%) was calculated as a ratio of standard deviation to mean blood glucose concentration multiplied by 100 .

\section{Preoperative fasting practice}

Even though all participants were requested to obey fasting after midnight prior to the day of surgery, except administration of carbohydrate-rich drink for the carbohydrate group, actual fasting time would be expected to differ. Patients were requested to record the time when they ceased ingestion of clear fluids and solid foods.

\section{Sample size determination and statistical analysis}

Sample size was predetermined by $t$ test Sample Size using SigmaPlot 12.5 (Systat Software Inc., USA) based on the assumption that patient well-being score, our primary endpoint, would exhibit a $20 \%$ difference and standard deviation (SD). A total of 43 patients were required for a significance level of 0.05 $(\alpha=0.05)$ and a power of $80 \%(\beta=0.20)$. Considering a dropout rate of $20 \%$, a total of 51 patients were recruited for the study.

Statistical analysis was performed with SigmaPlot 12.5. Continuous variables including patient demographics, NRS and coefficient of glucose variation were analyzed with Student's $t$ test or Mann-Whitney rank-sum test after normality test. Nonparametric variables including patient satisfaction were analyzed with the Mann-Whitney rank-sum test. Plasma glucose concentrations in both groups were analyzed with twoway repeated measures analysis of variance and Bonferroni $t$ test was used for post-hoc analysis. All data are expressed as the mean $\pm \mathrm{SD}$, median $\left(25^{\text {th }}-75^{\text {th }}\right.$ percentile $)$, percentage or the number of patients. A $\mathrm{P}$ value $\leq 0.05$ was considered statistically significant.

\section{Results}

Fifty-one patients were assessed for eligibility. One patient was excluded due to suspected undiagnosed diabetes mellitus (preoperative HbA1c 7.3\%, plasma glucose $173 \mathrm{mg} / \mathrm{dl}$ ). The subject flow is presented in Fig. 1. The two groups were homogenous in patient characteristics, anesthesia and surgery time and volume of fluids administered (Table 1). Seven parameters representing patient well-being (thirst, hunger, mouth dryness, nausea and vomiting, fatigue, anxiety, and sleep quality) were

Table 1. Patient Characteristics

\begin{tabular}{lccc}
\hline & $\begin{array}{c}\text { Control group } \\
(\mathrm{n}=25)\end{array}$ & $\begin{array}{c}\text { Carbohydrate group } \\
(\mathrm{n}=25)\end{array}$ & P value \\
\hline Sex (M/F) & $5 / 20$ & $6 / 19$ & 1.000 \\
ASA PS (I/II) & $17 / 8$ & $21 / 4$ & 0.321 \\
Age (yr) & $51.0 \pm 7.5$ & $49.8 \pm 7.1$ & 0.564 \\
Height (cm) & $160.1 \pm 6.7$ & $162.0 \pm 8.0$ & 0.379 \\
Weight (kg) & $62.0(55.0-71.2)$ & $64.5(56.0-71.8)$ & 0.560 \\
Anesthesia time & $108.4 \pm 16.5$ & $117.8 \pm 18.1$ & 0.064 \\
$\quad$ (min) & & & \\
Surgery time (min) & $74.0 \pm 15.8$ & $80.8 \pm 17.6$ & 0.157 \\
HbA1c (\%) & $5.5 \pm 0.3(5.1-6.1)^{*}$ & $5.6 \pm 0.3(5.1-6.4)^{*}$ & 0.200 \\
Fluid (ml/h/kg) & $3.8(2.8-5.3)$ & $4.3(2.9-4.7)$ & 0.923 \\
Actual fasting time & $720(720-840)$ & $720(690-840)$ & 0.685 \\
(min) & & & \\
\hline
\end{tabular}

Values are expressed as numbers, mean \pm SD or median (25th-75th percentile). *Ranges of plasma HbA1c level were expressed. Control group: midnight fasting group, Carbohydrate group: preoperative oral carbohydrate administration group. HbAlc: hemoglobin A1c also known as glycosylated hemoglobin.

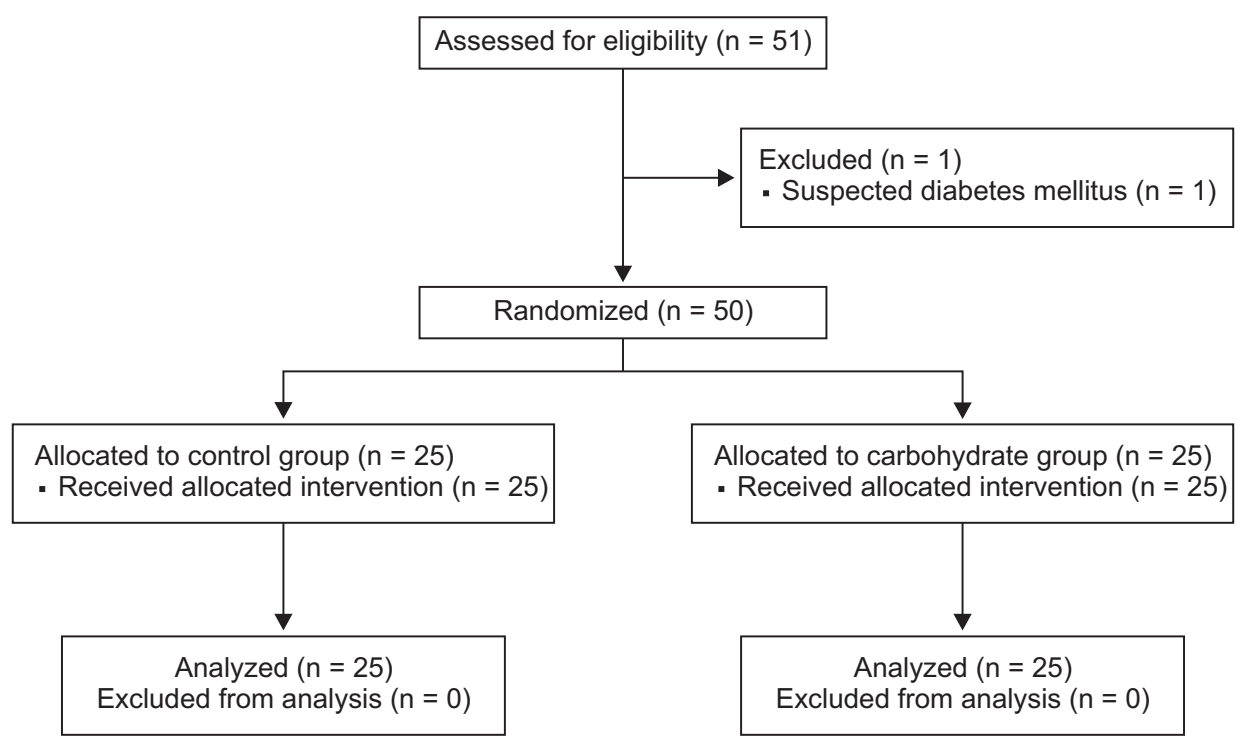

Fig. 1. Subject flow diagram. 
Table 2. Patient Well-being and Satisfaction

\begin{tabular}{|c|c|c|c|c|c|}
\hline & & \multicolumn{2}{|c|}{ Preoperative well-being } & \multicolumn{2}{|c|}{ Postoperative well-being } \\
\hline & & $\begin{array}{l}\text { Control group } \\
\quad(\mathrm{n}=25)\end{array}$ & $\begin{array}{l}\text { Carbohydrate } \\
\text { group }(\mathrm{n}=25)\end{array}$ & $\begin{array}{l}\text { Control group } \\
\quad(\mathrm{n}=25)\end{array}$ & $\begin{array}{l}\text { Carbohydrate } \\
\text { group }(\mathrm{n}=25)\end{array}$ \\
\hline \multirow[t]{3}{*}{ Thirst } & Median & 2 & 1 & 3 & 2 \\
\hline & IQR & $1-2$ & $0-2$ & $1.5-4$ & $1-3$ \\
\hline & $P$ value & 0.099 & & 0.456 & \\
\hline \multirow[t]{3}{*}{ Hunger } & Median & 1 & 1 & 1 & 1 \\
\hline & IQR & $0-2$ & $0-2$ & $0-2$ & $0-1$ \\
\hline & $P$ value & 1.000 & & 0.608 & \\
\hline \multirow[t]{3}{*}{ Mouth dryness } & Median & 1 & 1 & 3 & 2 \\
\hline & IQR & $0-1.5$ & $0-2$ & $2-3.5$ & $2-3.5$ \\
\hline & $P$ value & 0.864 & & 0.818 & \\
\hline \multirow[t]{3}{*}{ Nausea and vomiting } & Median & 0 & 0 & 1 & 1 \\
\hline & IQR & $0-0$ & $0-1$ & $1-2$ & $0.5-2$ \\
\hline & $P$ value & 0.192 & & 0.926 & \\
\hline \multirow[t]{3}{*}{ Fatigue } & Median & 2 & 2 & 1 & 1 \\
\hline & IQR & $1-2$ & $0-2$ & $0-2$ & $0.5-2$ \\
\hline & $P$ value & 0.512 & & 0.630 & \\
\hline \multirow[t]{3}{*}{ Anxiety } & Median & 3 & 2 & 0 & 0 \\
\hline & IQR & $2-3$ & $1-3$ & $0-1$ & $0-0$ \\
\hline & $P$ value & 0.288 & & 0.500 & \\
\hline \multirow[t]{3}{*}{ Sleep quality } & Median & 2 & 2 & 2 & 2 \\
\hline & IQR & $1-3$ & $1-3$ & $1-3.5$ & $1-3$ \\
\hline & $P$ value & 0.843 & & 0.223 & \\
\hline \multirow[t]{3}{*}{ Patient satisfaction* } & Median & 4 & 4 & 4 & 4 \\
\hline & IQR & $3-4$ & $3-4$ & $3-4$ & $3-4$ \\
\hline & P value & 1.000 & & 0.715 & \\
\hline
\end{tabular}

Seven parameters representing patient well-being (thirst, hunger, mouth dryness, nausea and vomiting, fatigue, anxiety, and sleep quality) were assessed using a numeric rating scale (0-10). ${ }^{*}$ Patient satisfaction was measured by a 5-point scale (5: very satisfied, 4: somewhat satisfied, 3: neutral, 2 : somewhat dissatisfied, 1: very dissatisfied). IQR: interquartile range.

Table 3. Oral Schirmer's Test

\begin{tabular}{lccc}
\hline & $\begin{array}{c}\text { Control } \\
\text { group }\end{array}$ & $\begin{array}{c}\text { Carbohydrate } \\
\text { group }\end{array}$ & P value \\
\hline $\begin{array}{c}\text { Rate of saliva secretion } \\
(\mathrm{mm} / 5 \mathrm{~min})^{*}\end{array}$ & $4.3(4.2-4.5)$ & $4.4(4.2-4.5)$ & 0.914 \\
\hline
\end{tabular}

*Length $(\mathrm{mm})$ of the wet portion on the filter paper by absorbing saliva for 5 minutes.

not statistically different between the two groups preoperatively and postoperatively (Table 2).

No significant differences in patient satisfaction scores and rate of saliva secretion (Table 3) were noted between the two groups. Plasma glucose concentrations were not statistically different between the two groups at each time point of intergroup analysis $(\mathrm{P}=0.691)$. In the control group, plasma glucose concentrations at 1 and 2 hours after anesthesia induction (T3 and T4) were significantly higher compared to that of anesthesia induction $(\mathrm{T} 2)(\mathrm{P}<0.001)$. In the carbohydrate group, plasma glucose concentrations at $\mathrm{T} 3, \mathrm{~T} 4$ and $\mathrm{T} 5$ were also significantly higher compared to that of T2 $(\mathrm{P}<0.001)$ (Fig. 2). Mean blood

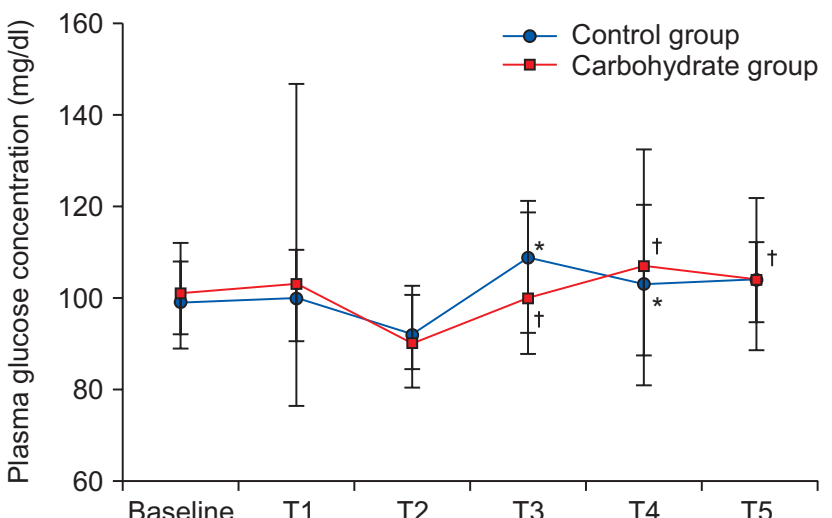

Fig. 2. Plasma glucose concentrations were not statistically different between two groups. *Plasma glucose concentrations at T3 and T4 were significantly higher than at $\mathrm{T} 2$ in control group $(\mathrm{P}<0.05) .{ }^{\dagger}$ Plasma glucose concentrations at T3, T4 and T5 were significantly higher than at T2 in carbohydrate group $(\mathrm{P}<0.05)$. Baseline: 2 hours before anesthesia induction, T1: 1 hour before anesthesia induction, T2: anesthesia induction, T3: 1 hour after anesthesia induction, T4: 2 hours after anesthesia induction, T5: 3 hours after anesthesia induction. 
Table 4. Intra-individual Glucose Variability

\begin{tabular}{lccc}
\hline & $\begin{array}{c}\text { Control } \\
\text { group }\end{array}$ & $\begin{array}{c}\text { Carbohydrate } \\
\text { group }\end{array}$ & P value \\
\hline $\begin{array}{l}\text { Mean blood glucose } \\
(\mathrm{mg} / \mathrm{dl})\end{array}$ & $100.7(93.8-104.4)$ & $99.7(96.8-108.7)$ & 0.961 \\
$\begin{array}{l}\text { SD of glucose } \\
\text { Coefficient of glucose } \\
\text { variation }(\%)^{*}\end{array}$ & $7.5(5.7-10.0)$ & $10.8(8.4-14.9)$ & 0.019 \\
\hline
\end{tabular}

*Coefficient of glucose variation (\%) was calculated as a ratio of standard deviation to mean blood glucose concentration multiplied by 100. SD: standard deviation.

glucose concentration SD and coefficient of glucose variations are presented in Table 4 . The mean blood glucose concentration similar between the two groups $(\mathrm{P}=0.961)$. However, a significant difference was observed in the SD of blood glucose concentration and coefficient of glucose variation $(\mathrm{P}<0.001)$. Coefficient of glucose variation (\%) was significantly higher in the carbohydrate group compared to the control group $(\mathrm{P}<0.001)$.

\section{Discussion}

This study examined the effects of preoperative oral carbohydrate administration on patient well-being and satisfaction in patients undergoing thyroidectomy. There was no significant improvement in patient well-being and satisfaction in patients who received a carbohydrate-rich drink preoperatively following an overnight fast compared to patients who fasted until the time of surgery. Hausel et al. [11] reported that preoperative oral carbohydrate administration improved preoperative hunger, anxiety and patient comfort compared to the midnight fasting group in patients undergoing major abdominal surgery. In another trial performed in an ophthalmologic day surgery setting, patients who received $200 \mathrm{ml}$ of a carbohydrate beverage preoperatively presented better satisfaction scores than midnight fasting patients [14]. However, those studies did not clarify the actual fasting time in either the control or the test group. Because a variety of fasting times can influence parameters of patient wellbeing such as thirst and hunger, the actual fasting time should be considered when interpreting the study results. Meanwhile, in the current study, we confined the enrollment of participants to only patients scheduled for surgery at 8:30 am to produce similar fasting time in the two groups, except for the controlled provision of the carbohydrate. The actual fasting time surveyed through patient questionnaires was 12 hours on average, and did not differ significantly in the two groups. Thus, our findings are reliable.

Surgery inevitably induces metabolic stress response and reduces insulin sensitivity. Insulin sensitivity can be reduced by over $50 \%$ even in healthy non-diabetic patients undergoing elec- tive surgery [15]. Insulin resistance occurs within hours after initiation of surgery, and subsequently results in hyperglycemia, a catabolic state characterized by degradation of stored glycogen, fat and protein, prolonged recovery and even increased morbidity $[16,17]$. Additionally, in terms of energy depletion pre- and post-operative fasting would aggravate the situation. Shortterm fasting causes insulin resistance even in healthy volunteers $[16,18]$. In terms of perioperative nutritional support, oral carbohydrate loading has been applied to patients undergoing elective surgery to improve clinical outcomes. Preoperative oral carbohydrate-rich drinks can improve patient well-being [10,11] as well as reduce metabolic stress and insulin resistance [5-7], improve postoperative recovery and reduce hospital stay $[8,9]$ in patients undergoing major abdominal surgery. But, more recently, meta- and network meta-analysis revealed that preoperative oral carbohydrate administration only slightly reduces length of hospital stay and improve insulin resistance compared with fasting, with no significant benefit concerning patient well-being $[3,8,9]$. Furthermore, the positive effects of preoperative oral carbohydrate intake have been suggested mainly in abdominal, orthopedic or cardiac surgery $[4,8,12,19-21]$, with little evidence for minor surgery patients.

The results of the current study may be explained partly by the relatively short fasting time and low surgical invasiveness. Preoperative fasting times in clinical practice were $>15$ hours for solid foods and $>12$ hours for clear liquid [22]. However, in the present study, the average fasting time was shorter (12 hours). Furthermore, because all participants were scheduled for the first surgery of the day, most of the fasting time would have been during nighttime sleep. Humans maintain normally and physiologically a fasted state during sleep without feeling of hunger or thirst. Furthermore, thyroid surgery may result in a surgical stress response that is too low to affect the clinical outcomes associated with oral carbohydrate administration, when compared to major abdominal surgery. Therefore, the authors presume that preoperative carbohydrate administration may have little effect in patients undergoing thyroidectomy in contrast to major surgical procedures.

Oral carbohydrate loading generally is not recommended for patients with diabetes mellitus due to concerns about uncontrolled hyperglycemia and delayed gastric empting [23]. We excluded subjects suspected of diabetes mellitus based on laboratory testing results of plasma glucose and $\mathrm{HbA1c}$. In the nondiabetic patients of our study, plasma glucose concentrations were maintained within the normal range until 5 hours even following administration of oral carbohydrate drink containing $12.8 \mathrm{~g} / 100 \mathrm{ml}$ of carbohydrate. Several previous studies have demonstrated that intravenous or oral carbohydrate administration increases plasma glucose and insulin concentrations [2426]. In a healthy volunteer study, plasma glucose concentration 
was increased 30 minutes following oral carbohydrate administration and returned to baseline within 90 minutes [26]. The reason for the different results in our study may be explained by the discrepancy between the timings of glucose measurement and the relative differences in insulin secretary functions of the individuals, even though plasma insulin concentrations were not evaluated.

During the perioperative period, increased glucose variability as well as hyperglycemia has been suggested to be associated with adverse patient outcome and increased mortality. Lanspa et al. [27] reported that coefficient of glucose variation was associated with 30-day mortality with an odds ratio of 1.23 for every $10 \%$ rise. Coefficient of glucose variation, which is the ratio of SD to mean blood glucose concentration, indicates intra-individual glucose variability. A higher coefficient of glucose variation may reflect the failure of glucose homeostasis. In our findings, coefficient of glucose variation was significantly higher in the carbohydrate group compared to the control group. However, even with a statistically significant difference, it may be difficult to assign a clinical significance to a difference of about $3 \%$. Further investigations should be conducted to assess whether and how increased glucose variability following carbohydrate administration can impact patient outcomes including length of hospital stay and postoperative complications.

The oral Schirmer's test is a modification of the Schirmer's eye test that can evaluate mouth dryness caused by hyposalivation $[13,28,29]$. Although we failed to prove the usefulness of the oral Schirmer's test in perioperative setting, the correlation between subjective outcomes such as mouth dryness and saliva secretory function could be investigated in a future study.

There are study limitations. First, the participants were not blinded to the allocated groups. Because we did not investigate placebo or water administration groups, but only fasting and carbohydrate administration groups, the participants could not be blinded. Secondly, we confined the enrollment of participants only to those scheduled for surgery at 8:30 am as a way to unify the fasting time in the two groups. Therefore, our findings may not be applicable to all patients under routine medical practice. Thirdly, the degrees of patient well-being and satisfaction were favorable even in the control group, perhaps due to the short fasting time, low surgical invasiveness of thyroidectomy and resultant minimal perioperative stress. So, the effects of preoperative oral carbohydrate administration would have not been appropriately revealed.

In conclusion, preoperative oral carbohydrate administration does not appear to improve patient well-being and satisfaction compared with midnight fasting in patients undergoing thyroidectomy in the first schedule in the morning. Further investigations of the effects of oral carbohydrate administration on other patient outcomes in various anesthetic or surgical settings should be performed.

\section{Conflicts of Interest}

This research received carbohydrate beverages (Nucare $\mathrm{NONPO}^{\circledR}$ ) from Daesang Wellife (Seoul, Korea).

\section{ORCID}

A Ram Doo, https://orcid.org/0000-0003-1310-790X

Dong-Chan Kim, https://orcid.org/0000-0002-6881-126X

\section{References}

1. Brady M, Kinn S, Stuart P. Preoperative fasting for adults to prevent perioperative complications. Cochrane Database Syst Rev 2003; (4): CD004423.

2. Ljungqvist O, Søreide E. Preoperative fasting. Br J Surg 2003; 90: 400-6.

3. Li L, Wang Z, Ying X, Tian J, Sun T, Yi K, et al. Preoperative carbohydrate loading for elective surgery: a systematic review and metaanalysis. Surg Today 2012; 42: 613-24.

4. Gustafsson UO, Scott MJ, Schwenk W, Demartines N, Roulin D, Francis N, et al. Guidelines for perioperative care in elective colonic surgery: Enhanced Recovery After Surgery (ERAS $\left({ }^{\circledR}\right)$ ) Society recommendations. World J Surg 2013; 37: 259-84.

5. Tamura T, Yatabe T, Kitagawa H, Yamashita K, Hanazaki K, Yokoyama M. Oral carbohydrate loading with $18 \%$ carbohydrate beverage alleviates insulin resistance. Asia Pac J Clin Nutr 2013; 22: 48-53.

6. Wang ZG, Wang Q, Wang WJ, Qin HL. Randomized clinical trial to compare the effects of preoperative oral carbohydrate versus placebo on insulin resistance after colorectal surgery. Br J Surg 2010; 97: 317-27.

7. Svanfeldt M, Thorell A, Hausel J, Soop M, Rooyackers O, Nygren J, et al. Randomized clinical trial of the effect of preoperative oral carbohydrate treatment on postoperative whole-body protein and glucose kinetics. Br J Surg 2007; 94: 1342-50.

8. Amer MA, Smith MD, Herbison GP, Plank LD, McCall JL. Network meta-analysis of the effect of preoperative carbohydrate loading on recovery after elective surgery. Br J Surg 2017; 104: 187-97.

9. Smith MD, McCall J, Plank L, Herbison GP, Soop M, Nygren J. Preoperative carbohydrate treatment for enhancing recovery after elective 
surgery. Cochrane Database Syst Rev 2014; (8): CD009161.

10. Sada F, Krasniqi A, Hamza A, Gecaj-Gashi A, Bicaj B, Kavaja F. A randomized trial of preoperative oral carbohydrates in abdominal surgery. BMC Anesthesiol 2014; 14: 93.

11. Hausel J, Nygren J, Lagerkranser M, Hellström PM, Hammarqvist F, Almström C, et al. A carbohydrate-rich drink reduces preoperative discomfort in elective surgery patients. Anesth Analg 2001; 93: 1344-50.

12. Yuill KA, Richardson RA, Davidson HI, Garden OJ, Parks RW. The administration of an oral carbohydrate-containing fluid prior to major elective upper-gastrointestinal surgery preserves skeletal muscle mass postoperatively--a randomised clinical trial. Clin Nutr 2005; $24: 32-7$.

13. López-Jornet P, Camacho-Alonso F, Bermejo-Fenoll A. A simple test for salivary gland hypofunction using Oral Schirmer's test. J Oral Pathol Med 2006; 35: 244-8.

14. Bopp C, Hofer S, Klein A, Weigand MA, Martin E, Gust R. A liberal preoperative fasting regimen improves patient comfort and satisfaction with anesthesia care in day-stay minor surgery. Minerva Anestesiol 2011; 77: 680-6.

15. Awad S, Constantin-Teodosiu D, Macdonald IA, Lobo DN. Short-term starvation and mitochondrial dysfunction - a possible mechanism leading to postoperative insulin resistance. Clin Nutr 2009; 28: 497-509.

16. Nygren J. The metabolic effects of fasting and surgery. Best Pract Res Clin Anaesthesiol 2006; 20: 429-38.

17. Soop M, Nygren J, Myrenfors P, Thorell A, Ljungqvist O. Preoperative oral carbohydrate treatment attenuates immediate postoperative insulin resistance. Am J Physiol Endocrinol Metab 2001; 280: E576-83.

18. Nygren J, Thorell A, Brismar K, Karpe F, Ljungqvist O. Short-term hypocaloric nutrition but not bed rest decrease insulin sensitivity and IGF-I bioavailability in healthy subjects: the importance of glucagon. Nutrition 1997; 13: 945-51.

19. Tran S, Wolever TM, Errett LE, Ahn H, Mazer CD, Keith M. Preoperative carbohydrate loading in patients undergoing coronary artery bypass or spinal surgery. Anesth Analg 2013; 117: 305-13.

20. Moppett IK, Greenhaff PL, Ollivere BJ, Joachim T, Lobo DN, Rowlands M. Pre-Operative nutrition In Neck of femur Trial (POINT)-carbohydrate loading in patients with fragility hip fracture: study protocol for a randomised controlled trial. Trials 2014; 15: 475.

21. Smith I, Kranke P, Murat I, Smith A, O'Sullivan G, Søreide E, et al. Perioperative fasting in adults and children: guidelines from the European Society of Anaesthesiology. Eur J Anaesthesiol 2011; 28: 556-69.

22. Pearse R, Rajakulendran Y. Pre-operative fasting and administration of regular medications in adult patients presenting for elective surgery. Has the new evidence changed practice? Eur J Anaesthesiol 1999; 16: 565-8.

23. Gustafsson UO, Nygren J, Thorell A, Soop M, Hellström PM, Ljungqvist O, et al. Pre-operative carbohydrate loading may be used in type 2 diabetes patients. Acta Anaesthesiol Scand 2008; 52: 946-51.

24. Helminen H, Viitanen H, Sajanti J. Effect of preoperative intravenous carbohydrate loading on preoperative discomfort in elective surgery patients. Eur J Anaesthesiol 2009; 26: 123-7.

25. Huh IY, Baek CH, Lee JD, Shin JW, Gwak MJ. Effects of fluid therapy on serum glucose level in pediatric outpatients. Korean J Anesthesiol 2006; 50: 158-61.

26. Svanfeldt M, Thorell A, Hausel J, Soop M, Nygren J, Ljungqvist O. Effect of "preoperative" oral carbohydrate treatment on insulin action--a randomised cross-over unblinded study in healthy subjects. Clin Nutr 2005; 24: 815-21.

27. Lanspa MJ, Dickerson J, Morris AH, Orme JF, Holmen J, Hirshberg EL. Coefficient of glucose variation is independently associated with mortality in critically ill patients receiving intravenous insulin. Crit Care 2014; 18: R86.

28. Garg AK, Malo M. Manifestations and treatment of xerostomia and associated oral effects secondary to head and neck radiation therapy. J Am Dent Assoc 1997; 128: 1128-33.

29. de Castro G Jr, Federico MH. Evaluation, prevention and management of radiotherapy-induced xerostomia in head and neck cancer patients. Curr Opin Oncol 2006; 18: 266-70. 